\title{
Analyzing the clinical profile of swine flu/influenza A H1N1 infection in central India: a retrospective study
}

\author{
Sameer Arbat ${ }^{1} \cdot$ Mitesh Dave $^{1} \cdot$ Vinit Niranjane $^{1} \cdot \operatorname{Irfan}_{\operatorname{Rahman}^{2}}^{2} \cdot$ \\ Ashok Arbat ${ }^{1}$
}

Received: 22 July 2016/ Accepted: 2 February 2017/Published online: 18 March 2017

(C) Indian Virological Society 2017

\begin{abstract}
Recently, India reported an increase in swine flu (influenza A H1N1) activity. There are limited studies on epidemiology of swine flu in Indian context. This study aims to analyze clinical and epidemiological profile of suspected swine flu cases in central India. 171 cases were included in a hospital based, observational, descriptive study conducted from December 2014 to April 2015. Demographics, clinical presentation and outcome of positive and negative cases were compared. Data was analyzed using STATA software. Distribution by age, sex and residence was found similar $(p>0.05)$ in positive and negative cases. Cough $(89 \%)$, fever $(85 \%)$ and throat irritation $(51 \%)$ were chief complaints (avg. duration $=4.9$ days). History of travel, history of contact with swine flu cases $(p=0.002)$ and history of visiting crowded places $(p=0.098)$ was reported considerably in higher proportion in positive cases as compared to negative cases. There were 14 deaths and they occurred significantly in younger age among positive cases as compared to negatives (Mean \pm SD: $34 \pm 2.8$ vs $47 \pm 8.4$ years). Case fatality ratio (CFR) in positive cases showing history of travel, contact with swine flu cases, requiring invasive ventilator support and $>3 \mathrm{X}$-ray zones involvement were significantly higher. Outbreak in later part of winter, high case fatality and younger population is more affected. In this study,
\end{abstract}

Ashok Arbat

Ashok_arbat@yahoo.com

1 Ketki Research Institute of Medical Sciences, 275, Central Bazar Road, Ramdaspeth, Nagpur, Maharashtra state 440 010, India

2 Department of Environmental Medicine and Pulmonary Medicine, University of Rochester Medical Center, Rochester, NY, USA swine flu infection and outbreaks started later in the year Hospital stay and CFR were increased. Understanding the swine flu infection, changing clinical presentation of swine flu and formulate new strategies for its prevention and management.

Keywords Influenza A virus $\cdot$ H1N1 subtype $\cdot$ Swine flu clinical profile $\cdot$ Case fatality ratio

\section{Introduction}

Influenza virus is a common human pathogen that has caused serious respiratory illness and death over the past century [1]. It always had potential to cause widespread pandemics whenever a new type of Influenza strain appeared in the human population and then spread easily from person to person [2]. Swine flu is an infection caused by any one of several types of swine influenza viruses, amongst which H1N1 influenza virus is the most common virus causing swine flu in humans. Symptoms of swine flu in humans are fever, chills, sore throat, cough muscle pains, headache, People who work with poultry and swine are at increased risk of zoonotic infection with influenza virus as this is endemic in these animals. The affected human can spread the virus to other human population via droplet or aerosol infection from coughing or sneezing or from fomites nearby the patient. This infection spreads so easily and has a high mortality and morbidity rate, therefore it has become an important public health problem and has potential to lead to frequent pandemics [2].

Recently, some countries in Northern Africa, Middle East, and notably India reported an increase in influenza A H1N1 activity [3]. It has been reported that the recent 2014-2015 H1N1 outbreak in India has resulted in $>8000$ 
Fig. 1 Time distribution of swine flu cases $(n=117)$. Daily frequency distribution of swine flu cases treated at Krims Hospital, Nagpur from 28th December 2014 to 14th April 2015

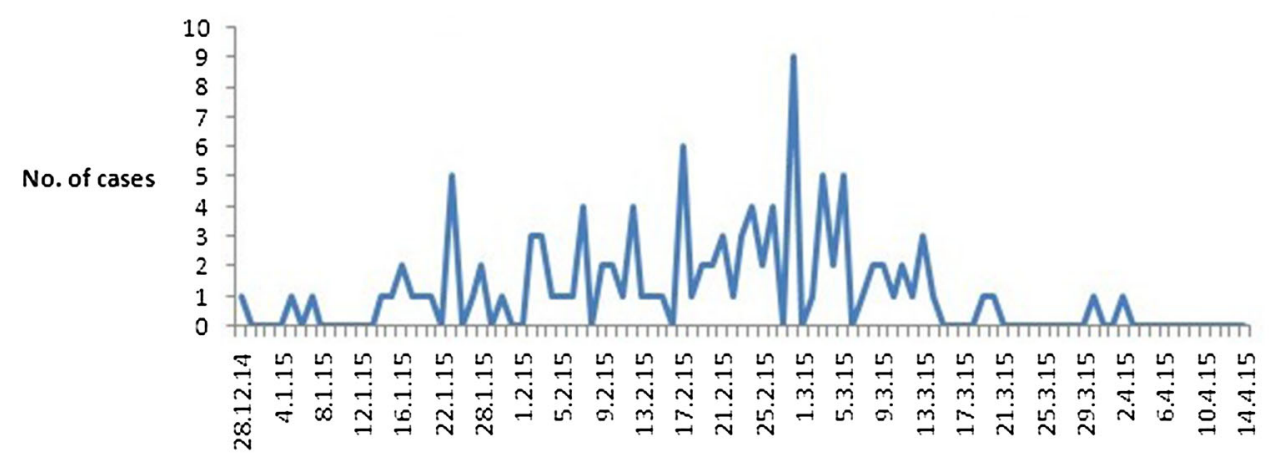

Dates cases with over 800 deaths [3]. Reports indicate that the majority of these cases involved young adults. H1N1 Strain A/California/04/2009_-was mainly responsible for this outbreak in India [3]. This study aims to evaluate clinical and epidemiological profile of suspected swine flu cases presenting at a tertiary level health care facility in central India. Further, this study is designed to determine if recent outbreak is any different from previous ones in Central India.

\section{Materials and methods}

\section{Study place and design}

A hospital based retrospective, analytical and descriptive study was conducted at KRIMS Hospital, Nagpur, India. The study protocol was approved by the local ethical committee of KRIMS.

\section{Study population}

The study population included 219 patients presenting to our Outpatient Department/In Patient department of KRIMS Hospital with suspected influenza like illness from December 2014 till mid April 2015.

\section{Statistical analysis}

Epidemiological characteristics were analyzed in terms of demographic variables, clinical presentation and outcome. Distribution of positive cases was studied by time, place and person.

Epidemiological characteristics of positive and negative cases were compared using Chi-square and Fisher's exact test. Case fatality among both the groups was also analyzed based on clinical characteristics. Data was analyzed using statistical STATA software. A $p$ value of less than 0.05 was considered to indicate statistical significance.
"History of travel" mentioned in the text refers to travelling history to local places nearby Nagpur (Maharashtra) or elsewhere but within India which may or may not be declared as Swine Flu affected region. "Visiting Crowded Places" means going to any place where there is a gathering of people e.g., social functions or gatherings.

\section{Results}

\section{Epidemiological profile}

A total of 171 cases were screened with $\mathrm{H} 1 \mathrm{~N} 1$ real-timePCR (RT-PCR) test at our hospital as described earlier [4]. Out of these, 117 of these were found to be tested positive and 54 tested negative. Time, Place, and Person (TPP) analysis was done for the positive cases.

Time distribution of swine flu cases in the series of patients admitted to study hospital during the outbreak in Nagpur region and surrounding areas during four months period from Dec 2014 to April 2015 is shown in Fig. 1. The epidemic curve suggests that there was a gradual increase in frequency with the swine flu epidemic reaching its peak between last week of February and first week of March and thereafter subsided slowly till first week of April 2015. The season from November to February marks winter period in India. In another study from India in 2009, maximum numbers of cases were observed in the month of December [1, 5]. The peak number of swine flu cases was in the months of July to September in another Indian study [6].

Geographical distribution of positive cases suggests that though swine flu epidemic was restricted to Nagpur city mostly. The majority $(n=66,56.4 \%)$ of 117 swine flu cases were reported from Nagpur city alone, 30 (25.6\%) cases from nearby districts in Vidarbha region. Around one-sixth $(15.4 \%)$ cases were also referred from districts of other adjoining states like Madhya Pradesh and Chattisgarh, as depicted in the spot map (Fig. 2). 


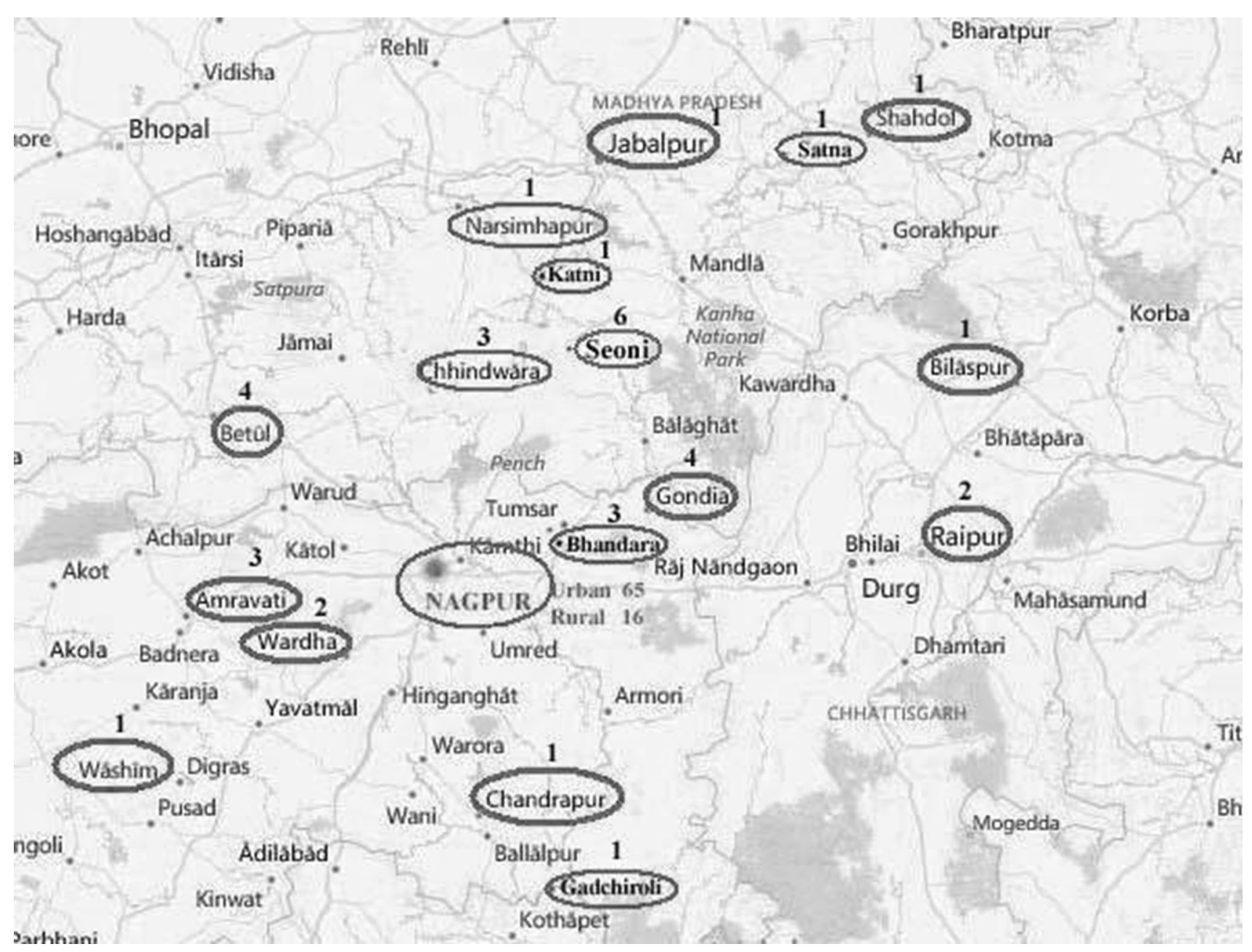

Fig. 2 Geographical distribution of swine flu cases in Central India region

\section{Clinical profile}

Distribution of positive and negative cases by Age, sex and residence was found almost similar $(p>0.05)$. Contrary to this, Revdiwala et al. [4] showed that H1N1 infection was more in males than females.

History of travel $(p=0.057)$, history of contact with swine flu patients $(p=0.002)$, history of visiting crowded places $(p=0.098)$ and social events was found in higher proportion in positive cases as compared to negative cases. History of travel was seen in $56 \%$ of positive cases. Chudasma et al. [5] reported only $1.1 \%$ swine flu patients having such travel history. While Pankaj et al. [7] reported $47 \%$ of positive patients having history of travel to swine flu infected areas or contact with the swine flu patients.

Cough (89\%), fever (85\%), throat irritation $(51 \%)$ and Dyspnoea (37\%) were the chief complaints in the present study. Fever, cough and headache were also predominant clinical manifestations reported by Talavera et al. [8] in
Southern Mexico, Cao et al. [9] in China, Jain et al. [10] in United States and Arun et al. [11] in India.

A significant difference was found in proportion of patients reporting with history of cough, fever and dyspnea in positive cases as compared to negative cases $(p=0.001)$. Mean duration of these conditions was 4.9 days ranging between 1 and 30 days.

Though not statistically significant, but mean $( \pm \mathrm{SD})$ hospital stay for positive cases ( $6 \pm 5.9$ days) was slightly more than that of negative cases ( $4.9 \pm 3$ days). Contrary to our study, several studies in different countries reported that rates of hospitalization were higher among females than males $[6,7,12,13]$.

Chest X-ray (CXR) involvement in form of one or more zones showing consolidation was seen in 59\% patients $(n=69)$ who tested positive for swine flu, $46 \%$ patients $(n=25)$ who were negative for swine flu. In a study of Revdiwala et al. [4] swine flu cases with bilateral consolidation were found in $53 \%$, left side consolidation 
in $29.4 \%$ and right side consolidation in $17.6 \%$ of patients. Another study found bilateral consolidation $18.58 \%$ of positive cases followed by left side $(10.62 \%)$ and right side $(8.85 \%)$ consolidation, while $61.95 \%$ CXR were normal [13].

\section{Mortality analysis}

Mean age at death among positive cases ( $47 \pm 8.4$ years) was higher $(p=0.056)$ as compared to negative cases (34 \pm 2.8 years) although not statistically significant.

Though not significant, but mortality in positive cases was found to be higher among males as compared to females. Mortality was also found more in rural versus urban residents, those with a travel history versus without such travel history (as 12 patients out of 14 who died had a history of travel), those with history of cough and fever versus without such history, and those with co-morbidities versus without any co-morbidities.

Mortality in positive cases showing $>3$ X-ray zones involvement was significantly higher $(p=0.033)$ as compared to those showing involvement up to 3 zones. Similarly significant findings were found for positive cases who received invasive ventilator support as compared to noninvasive one ( $p=0.033)$.

Average hospital stay in patients was 9.6 (range 1-37) days with a mean duration of symptoms of 5.5 (range 2-11) days. An earlier Indian study of 2009 swine flu pandemic found that expired cases had a much shorter mean stay of only 3.98 days [1].
Case fatality ratio (CFR \%) among positive cases was found significantly higher in patients aged $>35$ years $(p=0.0066)$, residents in rural area $(p=0.0021)$, and among those having history of contact with swine flu patient ( $p=0.0002)$. CFR was found more among males particularly in those having history of cough, fever and comorbidities, but these differences in comparison to females were not found statistically significant.

When case fatality risk analysis was done, CFR was found three times higher among positive cases as compared to negative cases; however the association was not found statistically significant (odds ratio $=3.0,95 \% \quad \mathrm{CI}$ $0.63-28.43, p=0.143$ ). An Indian study of 2009 reported a case fatality ratio of $26 \%$ [4], while in another Indian study of 2009-2010 it was reported $2 \%$ [11, 12].

The above results suggest that some factors like age (>35 years), invasive ventilator support, $>3$ X-ray zones involvement could be possible predictors of mortality in swine flu positive cases. Due to small sample size in comparison groups many other factors could not reach desired level of statistical significance.

\section{Discussion}

Study findings from this descriptive study suggests that age (>35 years), history of travel, history of contact with swine flu patients, invasive ventilator support and $>3$ X-ray zones involvement could be some important prognostic factors in this case series of swine flu patients from Central India.
Table 1 Comparison of positive and negative cases by socio-demographics and other clinical features of patients

\begin{tabular}{|c|c|c|c|c|c|c|}
\hline \multirow[t]{2}{*}{ Characteristic } & & \multicolumn{2}{|c|}{$\begin{array}{l}\text { Positive cases } \\
(\mathrm{n}=117)\end{array}$} & \multicolumn{2}{|c|}{$\begin{array}{l}\text { Negative cases } \\
(\mathrm{n}=54)\end{array}$} & \multirow[t]{2}{*}{$p$ value } \\
\hline & & Number & Percent & Number & Percent & \\
\hline \multirow[t]{2}{*}{ Age (years) } & Mean & 35.8 & Range 2-65 & 36.4 & Range 4-80 & 0.804 \\
\hline & SD & 17.6 & & 16.1 & & \\
\hline \multirow[t]{2}{*}{ Sex } & Male & 63 & 53.9 & 25 & 46.3 & 0.359 \\
\hline & Female & 54 & 46.1 & 29 & 53.7 & \\
\hline \multirow[t]{2}{*}{ Residence } & Rural & 49 & 41.9 & 24 & 44.4 & 0.753 \\
\hline & Urban & 68 & 58.1 & 30 & 55.6 & \\
\hline \multirow[t]{2}{*}{ Travel history } & Yes & 66 & 56.4 & 22 & 40.7 & 0.057 \\
\hline & No & 51 & 43.6 & 32 & 59.3 & \\
\hline \multirow[t]{2}{*}{ History of contact $\mathrm{H} 1 \mathrm{~N} 1$} & Yes & 17 & 14.5 & 0 & 0 & 0.002 \\
\hline & No & 100 & 85.5 & 54 & 100 & \\
\hline \multirow[t]{2}{*}{ Visiting crowded places } & Yes & 6 & 5.1 & 0 & 0 & 0.098 \\
\hline & No & 111 & 94.9 & 54 & 100 & \\
\hline \multirow[t]{2}{*}{ History of cough, fever } & Yes & 113 & 96.6 & 4 & 7.4 & 0.001 \\
\hline & No & 4 & 3.4 & 50 & 92.6 & \\
\hline \multirow[t]{2}{*}{ Co-morbidities } & Yes & 60 & 51.3 & 54 & 100 & 0.001 \\
\hline & No & 57 & 49.6 & 0 & 0 & \\
\hline Hospital stay (days) & Mean & 6.0 & Range 1-37 & 4.9 & Range $1-13$ & 0.423 \\
\hline
\end{tabular}


Patterns of swine flu infections are certainly changing in this area. As per our clinical exposure and data, previous swine flu outbreaks in central India usually started somewhat early, around September (rainy season), peak in December (winter season) and subsided by January. Children, women and middle-aged population used to be more vulnerable; hospital stay and CFR used to be relatively less. In our study swine flu outbreak, however started late, somewhere in December (winter season), peak in February and subside by April (summer season). We noticed young age patients more as is evident from Table 1 which shows mean age of patients to be 35.8 years. Hospital stay and CFR has also increased considerably, thereby putting a lot of pressure on health care system and draining the precious resources.

Table 2 Detailed analysis of deaths among positive and negative cases by various characteristics

\begin{tabular}{|c|c|c|c|c|c|c|}
\hline \multirow[t]{2}{*}{ Characteristic } & & \multicolumn{2}{|c|}{ Death in positive cases $(n=12)$} & \multicolumn{2}{|c|}{ Death in negative cases $(n=2)$} & \multirow[t]{2}{*}{$p$ value } \\
\hline & & Number & Percent & Number & Percent & \\
\hline \multirow[t]{2}{*}{ Age (years) } & Mean & 47 & Range 35-65 & 34 & Range $32-36$ & 0.056 \\
\hline & SD & 8.4 & & 2.8 & & \\
\hline \multirow[t]{2}{*}{ Sex } & Male & 7 & 58.3 & 1 & 50 & 0.692 \\
\hline & Female & 5 & 41.7 & 1 & 50 & \\
\hline \multirow[t]{2}{*}{ Residence } & Rural & 10 & 83.3 & 1 & 50 & 0.396 \\
\hline & Urban & 2 & 16.7 & 1 & 50 & \\
\hline \multirow[t]{2}{*}{ Travel history } & Yes & 6 & 50 & 2 & 100 & 0.308 \\
\hline & No & 6 & 50 & 0 & 0 & \\
\hline \multirow[t]{2}{*}{ History of cough, fever } & Yes & 12 & 100 & 2 & 100 & - \\
\hline & No & 0 & 0 & 0 & 0 & \\
\hline \multirow[t]{2}{*}{ Co-morbidities } & Yes & 9 & 75 & 1 & 50 & 0.505 \\
\hline & No & 3 & 25 & 1 & 50 & \\
\hline \multirow[t]{2}{*}{ X-ray zone } & Up to 3 & 1 & 8.3 & 2 & 100 & 0.033 \\
\hline & 4 or $4+$ & 11 & 91.7 & 0 & 0 & \\
\hline \multirow[t]{2}{*}{ Ventilator support } & Invasive & 11 & 91.7 & 0 & 0 & 0.033 \\
\hline & NIV & 1 & 8.3 & 2 & 100 & \\
\hline
\end{tabular}

$N I V$ non invasive ventilation

Table 3 H1N1 case fatality ratio in positive and negative by their socio-demographic and clinical characteristics

\begin{tabular}{|c|c|c|c|c|c|}
\hline \multirow[t]{2}{*}{ Characteristic } & & \multicolumn{2}{|c|}{ CFR in positive cases $(n=117)$} & \multicolumn{2}{|c|}{ CFR in negative cases $(n=54)$} \\
\hline & & Number & Percent & Number & Percent \\
\hline \multirow[t]{2}{*}{ Age (years) } & $>35$ & $11 / 64$ & $17.19 * *$ & $1 / 24$ & 4.17 \\
\hline & $\leq 35$ & $1 / 53$ & 1.89 & $1 / 30$ & 3.33 \\
\hline \multirow[t]{2}{*}{ Sex } & Male & $7 / 54$ & 12.96 & $1 / 29$ & 3.45 \\
\hline & Female & $5 / 63$ & 7.94 & $1 / 25$ & 4.0 \\
\hline \multirow[t]{2}{*}{ Residence } & Rural & $10 / 49$ & $20.41 * *$ & $1 / 24$ & 4.17 \\
\hline & Urban & $2 / 68$ & 2.94 & $1 / 30$ & 3.33 \\
\hline \multirow[t]{2}{*}{ Travel history } & Yes & $6 / 66$ & 9.09 & $2 / 22$ & 9.090 \\
\hline & No & $6 / 51$ & 11.76 & $0 / 32$ & \\
\hline \multirow[t]{2}{*}{ Contact with H1N1 } & Yes & $6 / 17$ & $35.29 * *$ & 0 & 0 \\
\hline & No & $6 / 100$ & 6.0 & $2 / 54$ & 3.7 \\
\hline \multirow[t]{2}{*}{ Crowded place visit } & Yes & $0 / 6$ & 5.1 & 0 & 0 \\
\hline & No & $12 / 111$ & 10.81 & $2 / 54$ & 3.7 \\
\hline \multirow[t]{2}{*}{ History of cough, fever } & Yes & $12 / 113$ & 10.62 & $1 / 4$ & 25.0 \\
\hline & No & $0 / 4$ & 0 & $1 / 50$ & 2.0 \\
\hline \multirow[t]{2}{*}{ Co-morbidities } & Yes & $9 / 60$ & 15.0 & $2 / 54$ & 3.7 \\
\hline & No & $3 / 57$ & 5.26 & 0 & 0 \\
\hline
\end{tabular}

** $p<0.001=$ highly significant 
This study has some inherent limitations hence study findings should be interpreted cautiously. Retrospective nature, small sample size, institutionalized study setting and convenience sampling were some methodological pitfalls that might affect the scientific validity and reliability of the conclusions and diminish its generalizability to other populations. Further, lack of sampling for viral titers due to urgent care, and devoid of spirometry was limitations (Table 2).

Despite these limitations, findings of this study have certainly been important as they have shed light on time, place and person (TPP) distributions of swine flu cases and related deaths in Central India population. The region is known to have a typical climate with extreme heat, rains and winter conditions. The study findings provides data on magnitude, severity and some possible prognostic factors of swine flu cases pertaining to Central India. Larger, community-based studies backed by stronger study design may provide better clues for understanding epidemiology of swine flu outbreaks and help to plan measures for control of this infection in regional population (Table 3).

\section{References}

1. Vijaydeep S, Vineet G, Vipin K. Clinical-epidemiological profile of influenza A H1N1 cases at a Tertiary Care Institute of India. Indian J Community Med. 2012;37(4):232-5.

2. Khanna M, Kumar P, Choudhary K, Kumar B. Emerging influenza virus: a serious global threat. J Biosci. 2008;33:475-82.
3. Tharakaraman K, Sasisekharan R. Influenza surveillance: 2014-2015 H1N1 "swine"'-derived influenza viruses from India. Cell Host Microbe. 2015;17(3):275-416.

4. Revdiwala S, Mulla S, Panwala T, et al. Clinical characterisation of H1N1 influenza Taqman real time PCR positive cases. Natl J Med Res. 2012;2(1):12-4.

5. Rajesh KC, Umed VP, Pramod BV, et al. Clinico epidemiological features of the hospitalized patients with 2009 pandemic influenza A (H1N1) virus infection in Saurashtra region. Lung India. 2011;28(1):11-6.

6. Kashinkunti MD, Gundikeri SK, Dhananjaya M. Study of clinical profile of patients with H1N1 influenza in a teaching hospital of North Karnataka. IJRRMS. 2013;3(3):53-55

7. Pankaj KM, Jadab CS, Biswanath B. Clinical profile of H1N1 influenza: a hospital based epidemiological study in Kolkata, India. Sudan J Public Health. 2013;8(1):21-4.

8. Guadalupe AT, Miguel BC, Jesús GC, et al. Epidemiologic study of human influenza A (H1N1) pdm09 virus in Yucatan, Southern Mexico. Rev Biomed. 2012;23:39-46.

9. Cao B, Li XW, Mao Y, et al. Clinical features of the initial cases of 2009 Pandemic influenza A (H1N1) virus infection in China. N Engl J Med. 2009;361:2507-17.

10. Jain S, Kamimoto L, Bramley AM, et al. Pandemic influenza A (H1N1) virus hospitalizations investigation team. Hospitalized patients with H1N1 influenza in the United States. N Engl J Med. 2009;361:1935-44.

11. Arun YH, Subhash BT, Suresh MU, et al. An epidemiological investigation of influenza like illness to confirm H1N1 among patients admitted to tertiary care hospital of Nagpur. Int J Sci Res Publ. 2013;3(8):1-6.

12. Puvanalingam A, Rajendiran C, Sivasubramanian K, Ragunanthanan S, Sarada Suresh S, Gopalakrishnan S. Case series study of the clinical profile of H1N1 swine flu influenza. J Assoc Phys India. 2011;59:14-8.

13. Prakash G. Epidemiological and clinical profile of patients with swine flu attending Guru Govindsingh Government Hospital, Jamnagar, India. J Res Med Dent Sci. 2013;1(1):1-6. 